\title{
Versatilidad del colgajo Estlander en reconstrucción de labio
}

\author{
Versatility of Estlander flap in lip reconstruction \\ Dr. Jesús Fernando Romero-Espinosa,* Dra. Andrea Del Villar-Trujillo,* \\ Dra. Mónica Gisela Cobos-Bonilla, ${ }^{\ddagger}$ Dr. Felipe Hernández-Aguilar, $\$$ \\ Dra. Ivonne Castrejón-Castro, " Dr. Mauro Lozada-Salgado ${ }^{\S}$
}

Palabras clave: Reconstrucción de labio, colgajo Estlander, colgajo local.

Keywords: Lip reconstruction, Estlander flap, local flap.

\footnotetext{
* Jefe.

‡ Residente de cuarto

año.

$\S$ Adscrito.

" Residente de segundo año.

Servicio de Cirugía Plástica y Reconstructiva. Centro Médico «Lic. Adolfo López Mateos».

Recibido:

17 mayo 2020 Aceptado para publicar: 13 julio 2020
}

\section{RESUMEN}

La reconstrucción del labio a nivel de la comisura labial puede ser desafiante, siendo ideal la preservación de la sonrisa con la elevación de la neocomisura, evitando el desplazamiento y asimetría de la cara. El propósito de este estudio fue evaluar la eficacia del colgajo Estlander en la reconstrucción de defectos de la comisura labial en dos pacientes. El colgajo Estlander puede utilizarse para la reconstrucción primaria del labio, secundaria a defectos de la comisura labial y reconstrucción de defectos que van de uno a dos tercios del labio que incluyen la comisura; es una opción adecuada para preservar la estética y función de la cara. La cicatrización de las heridas se logró en dos semanas después de la intervención y la cicatriz apenas se nota después de un mes.

\section{ABSTRACT}

Reconstruction of the lip at the level of the corner of the mouth can be challenging. The preservation of one's smile with the elevation of the new commissure is ideal, avoiding displacement and asymmetry of the face. The purpose of this study was to evaluate the efficacy of the Estlander flap in the reconstruction of defects of the corner of the mouth in two patients. The Estlander flap can be used for the primary reconstruction of the lip, secondary to defects of the corner of the mouth and reconstruction of defects ranging from one to two thirds of the lip that include the commissure, an appropriate option to preserve the aesthetics and function of the face. The healing of the wounds was achieved in two weeks after the intervention and the scar was barely noticeable after a month.

\section{INTRODUCCIÓN}

L os labios son estructuras complejas que desempeñan un papel esencial en la estética y en diferentes funciones como la nutrición, el habla, la expresión facial y como símbolo de belleza. ${ }^{1}$ Para los ancianos, los labios también tienen un papel importante para la masticación y el ajuste de la dentadura. ${ }^{2}$

La reconstrucción de defectos en los labios requiere una comprensión sólida no sólo de la anatomía, sino de la función. Los labios superior e inferior funcionan como un esfínter que facilita la masticación y la fonación. El labio superior protege la dentición y el labio inferior evita la salida no deseada de secreciones orales, ${ }^{3}$ por lo que la afección, sea superior o inferior, afecta la funcionalidad ocasionando sialorrea debido a la baja posibilidad de contención de la misma. ${ }^{4,5}$

Ciertas afecciones como el cáncer, traumatismos y deformidades congénitas son las principales causas de dimorfismo labial que requieren reconstrucción. ${ }^{1}$ El carcinoma de células escamosas labiales (CEC) es una de las

Citar como: Romero-Espinosa JF, Del Villar-Trujillo A, Cobos-Bonilla MG, Hernández-Aguilar F, Castrejón-Castro I, Lozada-Salgado M. Versatilidad del colgajo Estlander en reconstrucción de labio. Cir Plast. 2020; 30 (2): 126-132. https://dx.doi.org/10.35366/97677 
principales causas de defectos que deben reconstruirse; representa de 12 a 30\% del cáncer de la cavidad oral y aumenta la proporción de incidencia en la población de edad avanzada. La mayoría de los tipos de cáncer está relacionada con los labios (95\%) y el labio inferior está más frecuentemente involucrado en comparación con el labio superior (90\%: 10\%), lo que se asocia con un alto nivel de exposición a la radiación ultravioleta, radioterapia previa y condiciones precancerosas en general. $2,6,7$

El labio superior es una estructura trilaminar donde el músculo orbicular es el esfínter oral y el modiolo se encuentra en el ángulo de la boca formando una compleja organización de músculos, lo que permite su apertura y cierre. El músculo orbicularis oris es el principal músculo intrínseco de la boca, especialmente del modiolo. El músculo orbicular es uno de los 14 músculos faciales según la clasificación de Nairn. ${ }^{8}$ Las arterias labiales son tortuosas y discurren entre la mucosa y el músculo orbicular. Las columnas filtrares son puentes musculocutáneos, los cuales están formados por la inserción de las fibras músculo orbicular contralateral. Las columnas filtrares con frecuencia cuentan con depresor septal en la base medial. ${ }^{9}$ El origen de la arteria labial superior se localiza al mismo nivel superior de la comisura labial y se origina de la arteria facial. ${ }^{10}$

Los objetivos funcionales de la reconstrucción labial incluyen el mantenimiento de la competencia oral, el acceso oral suficiente y la preservación de la sensación labial. ${ }^{1,3}$ La parte principal de los resultados estéticos está relacionada con la simetría y el equilibrio. La realineación adecuada de las fibras del orbicular oris conduce a restaurar la función normal del esfínter y disminuye la probable distorsión durante los movimientos faciales. ${ }^{11}$
Desde mediados del siglo XIX se han descrito más de 200 técnicas diferentes para la reconstrucción del labio inferior. El concepto de unidades estéticas de la cara, introducido por González-Ulloa en 1956 para la reconstrucción de quemaduras, se ha convertido en una herramienta importante para un enfoque sistemático en la reconstrucción facial, principalmente para la cirugía de la nariz. En el tratamiento del cáncer de labio, el concepto de las unidades estéticas de la cara no se ha tenido en cuenta sistemáticamente. Éste es un aspecto muy importante al elegir la técnica operativa correcta. ${ }^{11,12}$

La reconstrucción de labio depende del tamaño del defecto, la localización y la elasticidad de los tejidos. También hay factores que afectan la evolución del paciente como la edad, comorbilidades y actitud del paciente ante su reconstrucción. ${ }^{13}$

El colgajo de Abbe-Estlander es un colgajo de espesor completo de forma triangular que crea la comisura labial y la parte lateral del labio inferior o superior y está irrigado por la arteria labial superior o inferior opuesta. ${ }^{14}$ Descrito en 1872, este colgajo se ha utilizado principalmente en la afectación de la comisura. ${ }^{3}$ En 1898 Abbe fue el primero en cambiar un colgajo de labio inferior al labio superior para una deformidad hendida. Este colgajo comienza desde la parte medial de la comisura labial con una dimensión aproximada de $1.5 \times 3 \mathrm{~cm}$ y la rotación directa al defecto se completa en una etapa. ${ }^{1,11}$ La modificación que hizo Templer se basa en tomar el colgajo desde el ala nasal a nivel del surco, pasando por el vestíbulo nasal atravesando el filtrum para poder rotarlo, tomando en cuenta que su límite máximo superior de anchura debe de ser la mitad de ancho del
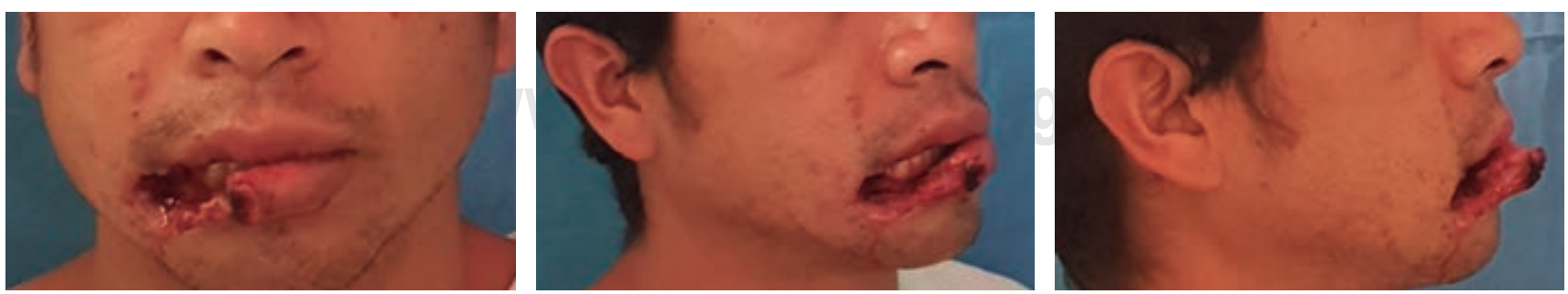

Figura 1: Imágenes preoperatorias. Lesión en unidad estética del labio interior con avulsión de más de 40\% de la superficie, de espesor total del labio, con pérdida de competencia oral. 


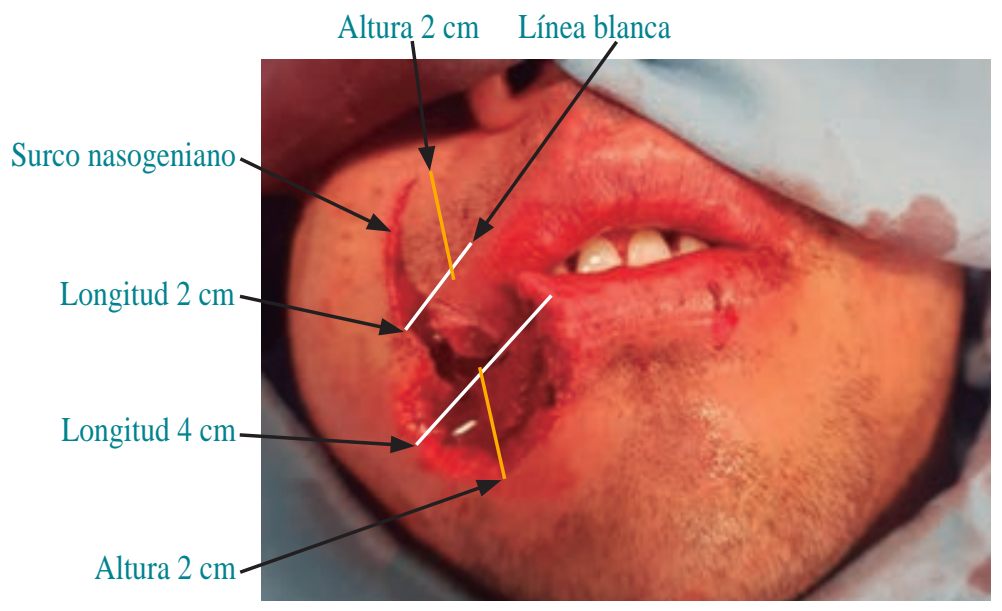

Figura 2: Marcaje quirúrgico. Se identifica la longitud del colgajo: es la mitad de la longitud del defecto y la altura es igual a la altura del defecto.
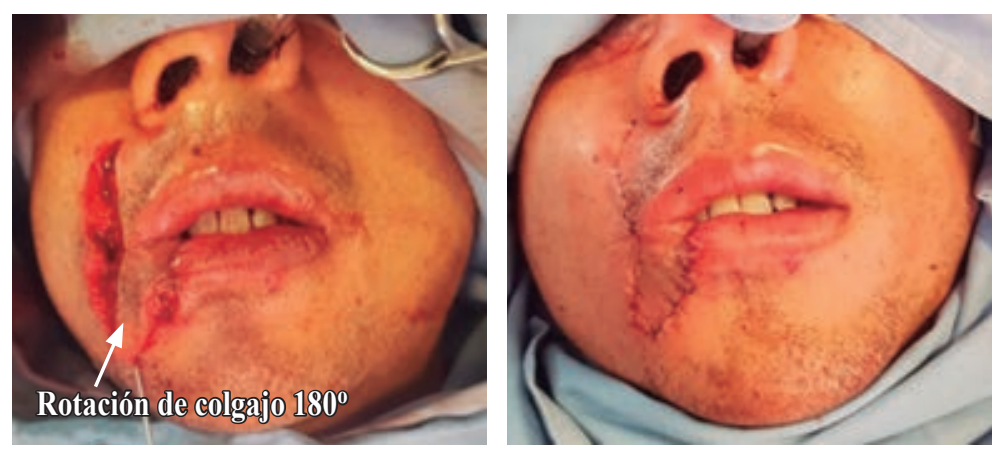

Figura 3: Técnica quirúrgica. Incisión en los tres planos: piel, músculo orbicular y mucosa, posteriormente en el borde interno del labio se realiza la resección hasta antes de llegar al bermellón, respetando la línea blanca.

defecto, por lo que si tenemos un defecto de 4 $\mathrm{cm}$ como máximo se puede realizar el colgajo de $2 \mathrm{~cm}$ de forma segura. ${ }^{15}$

El propósito de este estudio fue evaluar la eficacia del colgajo Estlander en la reconstrucción de defectos de la comisura labial en dos pacientes.

\section{CASOS CLÍNICOS}

\section{Caso 1}

Hombre de 33 años de edad que inició padecimiento cuando se encontraba con unos amigos tomando bebidas alcohólicas; empezaron a discutir y uno de sus compañeros lo mordió, ocasionando avulsión de la unidad estética del labio inferior (Figura 1). En quirófano se realizó marcaje quirúrgico, identificando la longitud del colgajo basado en la mitad de la longitud del defecto así como la altura del defecto con el mismo margen para el alto del colgajo (Figura 2). Se procedió a desbridar zona receptora, e identificar planos. Se realizó incisión con bisturí frío de todos los espesores (piel, músculo orbicular y mucosa), seccionándolos por completo, posteriormente en el borde interno del labio se realizó la resección hasta antes de llegar al bermellón, respetando la línea blanca; se rotó el colgajo $180^{\circ}$ (Figura 3) y se cerró por planos, iniciando a nivel de mucosa oral con Vicryl 3-0 después el músculo orbicular, se identificó la nueva comisura y se fijó al modiolo. Se afrontó el tejido celular subcutáneo con Vicryl 4-0 y la piel con nylon 5-0. El resultado quirúrgico a los siete días y a los seis meses fue satisfactorio (Figura 4).

\section{Caso 2}

Mujer de 60 años de edad quien inició padecimiento dos años antes al presentar tumoración a nivel de la unidad estética del labio superior con incremento de tamaño. Se realizó biopsia con resultado positivo a carcinoma basocelular que incluía piel, tejido celular subcutáneo, músculo orbicular y mucosa. Se envió a nuestro servicio y se programó para tratamiento quirúrgico radical (Figura 5). Se realizó marcaje quirúrgico (Figura 6) tomando medidas de la tumoración respetando un margen de $7 \mathrm{~mm}$ (las medidas de la tumoración fueron de $2.5 \times 3 \mathrm{~cm}$ ). Se inició marcaje quirúrgico perpendicular al arco de cupido hasta llegar a la base nasal, rodeando y uniendo una línea con el surco nasogeniano hasta la comisura labial; se marcó el labio inferior respetando las líneas de relajación de tensión de la piel (RTLS), tomando un colgajo de $2 \times 1.5 \mathrm{~cm}$. Se incidió respetando la arteria labial inferior en su porción media, preservando en su porción medial el bermellón y se incidió hasta la línea blanca para preservar la arteria labial inferior. Se incidió piel, tejido celular subcutáneo, músculo orbicular y mucosa y en su porción media se respetó todo el labio desde la línea blanca hasta su interior. Se rotó $180^{\circ}$ y se procedió a colocar puntos de afrontamiento (Figura 7), identificando el modiolo y se llevó la nueva comisura labial a este punto para preser- 
var la sonrisa. Se cerró la mucosa con Vicryl 3-0, músculo orbicular con Vicryl 3-0, tejido celular subcutáneo y piel con nylon 6-0. El resultado quirúrgico a los siete días y a los seis meses fue satisfactorio (Figura 8).

\section{DISCUSIÓN}

Los labios son estructuras complejas de la cara que tienen un papel esencial en la estética. Los cuatro objetivos principales de una función oral adecuada son la competencia oral, función muscular, sensación del labio y competencia oral.
Los objetivos cosméticos de la reconstrucción del labio incluyen restaurar la simetría labial, apertura oral adecuada y evitar cicatrices. Si bien los objetivos cosméticos son un punto clave, es importante recordar que no importa cuán buena se vea una reconstrucción labial, la función labial y la competencia oral son los determinantes clave de una reconstrucción exitosa.

El cirujano reconstructivo tiene un gran número de opciones quirúrgicas para la reconstrucción del labio. Un análisis detallado del defecto es esencial para la selección del método reconstructivo adecuado.
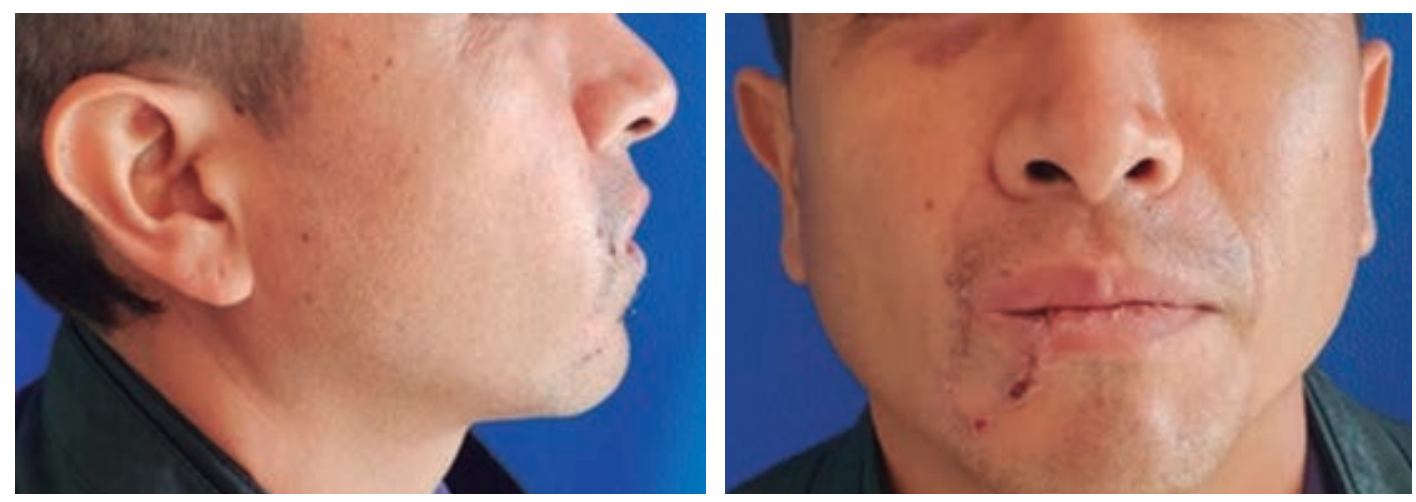

Figura 4:

Resultado postoperatorio a los siete días y seis meses.
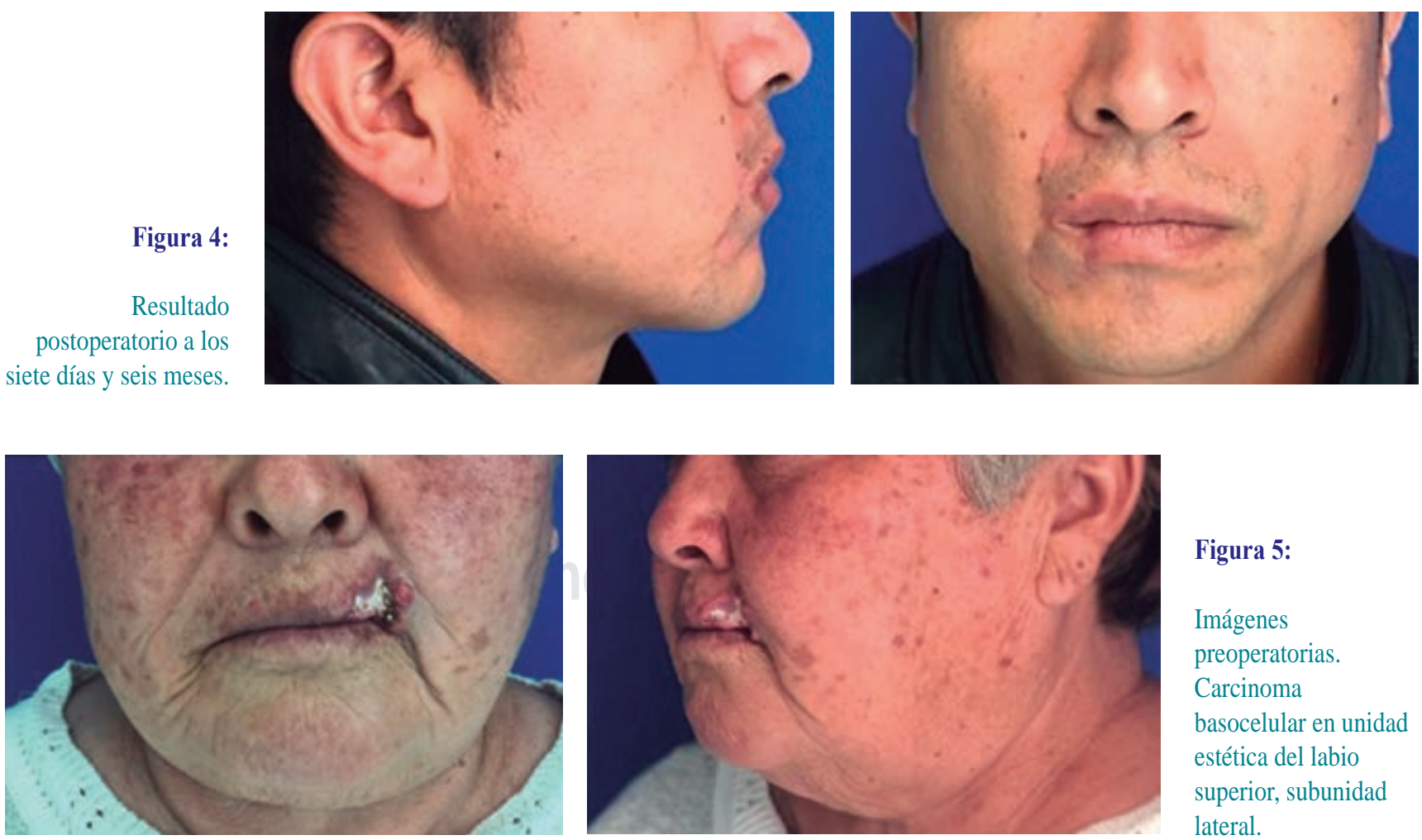

Figura 5:

Imágenes

preoperatorias.

Carcinoma

basocelular en unidad estética del labio superior, subunidad lateral. 


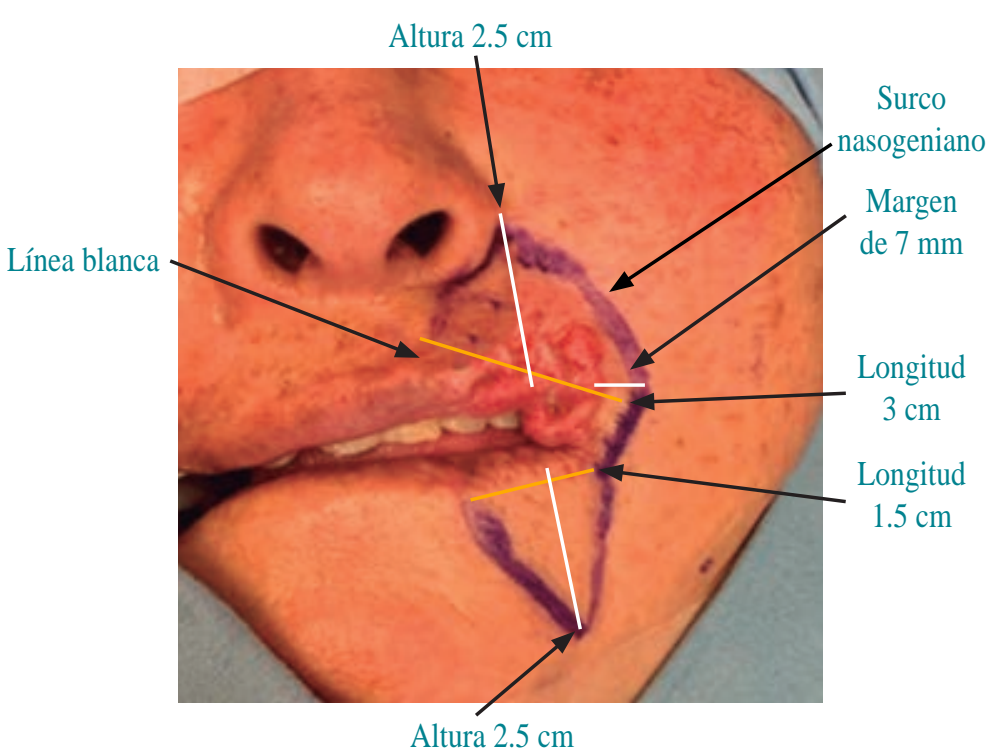

Figura 6: Marcaje quirúrgico.
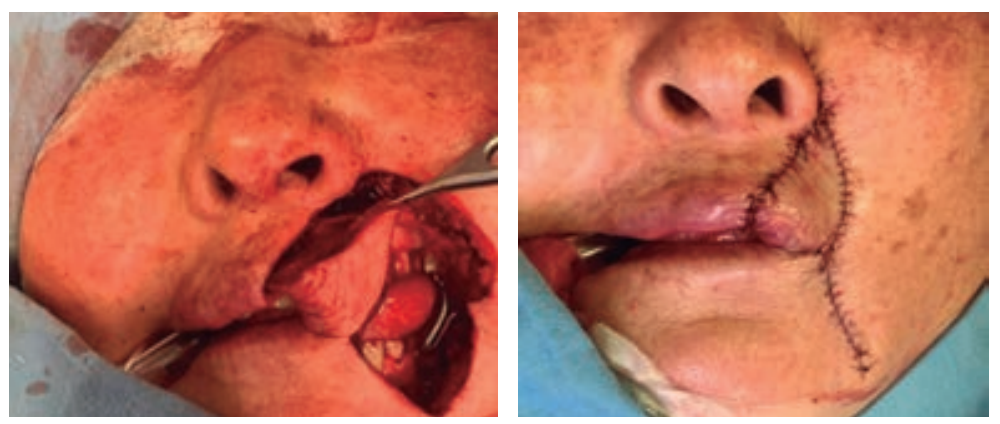

Figura 7: Técnica quirúrgica: realizar movimiento de colgajo para cobertura del labio superior con un giro de $180^{\circ}$.

Uno de los aspectos más importantes a considerar en la reconstrucción del labio, comprende la restauración de la función (motora y sensitiva) y estética facial. Ciertas afecciones como el cáncer, traumatismos y deformidades congénitas son las principales causas de dimorfismo labial que requieren reconstrucción. Las etiologías en nuestros pacientes fueron las dos causas más frecuentes reportadas en la literatura. El primer paciente, con defecto secundario a trauma y la segunda, con carcinoma basocelular; ambos pacientes presentan adecuada simetría y preservación de la sonrisa con la adecuada fijación de la nueva comisura al modiolo. Para poder marcar adecuadamente el colgajo de labio superior para labio inferior se debe tomar el surco nasolabial, el cual corre por el ala nasal, Ilega al vestibular y toma la base columelar. ${ }^{16}$

La técnica propuesta Yamauchi M comenta que la incisión se debe realizar en el espesor total hasta llegar al borde del bermellón, respetando éste para preservar la irrigación de la arteria labial superior. Es importante que al momento de realizar el giro del colgajo se pueda observar la posición del pedículo. Se debe prestar atención al momento de realizar el cierre, ya que el músculo cigomático mayor y menor así como el risorio y bucinador se deben suturar al músculo orbicular para generar una adecuada tensión. ${ }^{7,17}$

La desventaja principal es que el colgajo involucra la comisura labial con un aspecto romo, que en algunos casos no es muy notorio con la boca cerrada, pero se hace obvio al abrir la boca (Figura 9). En nuestros casos observamos una ligera asimetría, pero creemos que el resultado final fue positivo teniendo en cuenta que la lesión afectaba más de dos tercios del labio inferior y superior, que a menudo requieren comisuroplastias.

La comisuroplastia se describió hace más de 150 años, todavía mantiene una posición confiable como método de reconstrucción de labios debido a sus resultados en funcionalidad (cierre, apertura, fonación y continencia). Sus principales desventajas son la microstomía y la desaparición de la comisura.

La necesidad de un segundo procedimiento quirúrgico es común y se debe realizar a las 12 semanas para mejorar ciertos aspectos que involucran el resultado; sin embargo, en el estudio realizado por Kumar y colaboradores de 10 pacientes se obtuvieron resultados adecuados en nueve de estos pacientes con un solo procedimiento.

Las complicaciones postoperatorias después de la reconstrucción del labio inferior varían según el procedimiento. En el caso del colgajo de Estlander y otros colgajos locales son la pérdida del colgajo, embotamiento de la comisura reparada, asimetría labial, pérdida sensorial, hipersensibilidad, edema, microstomía, poca competencia oral con babeo y cicatrices indeseables. ${ }^{2,7}$ Los resultados cosméticos obtenidos en nuestros pacientes fueron 

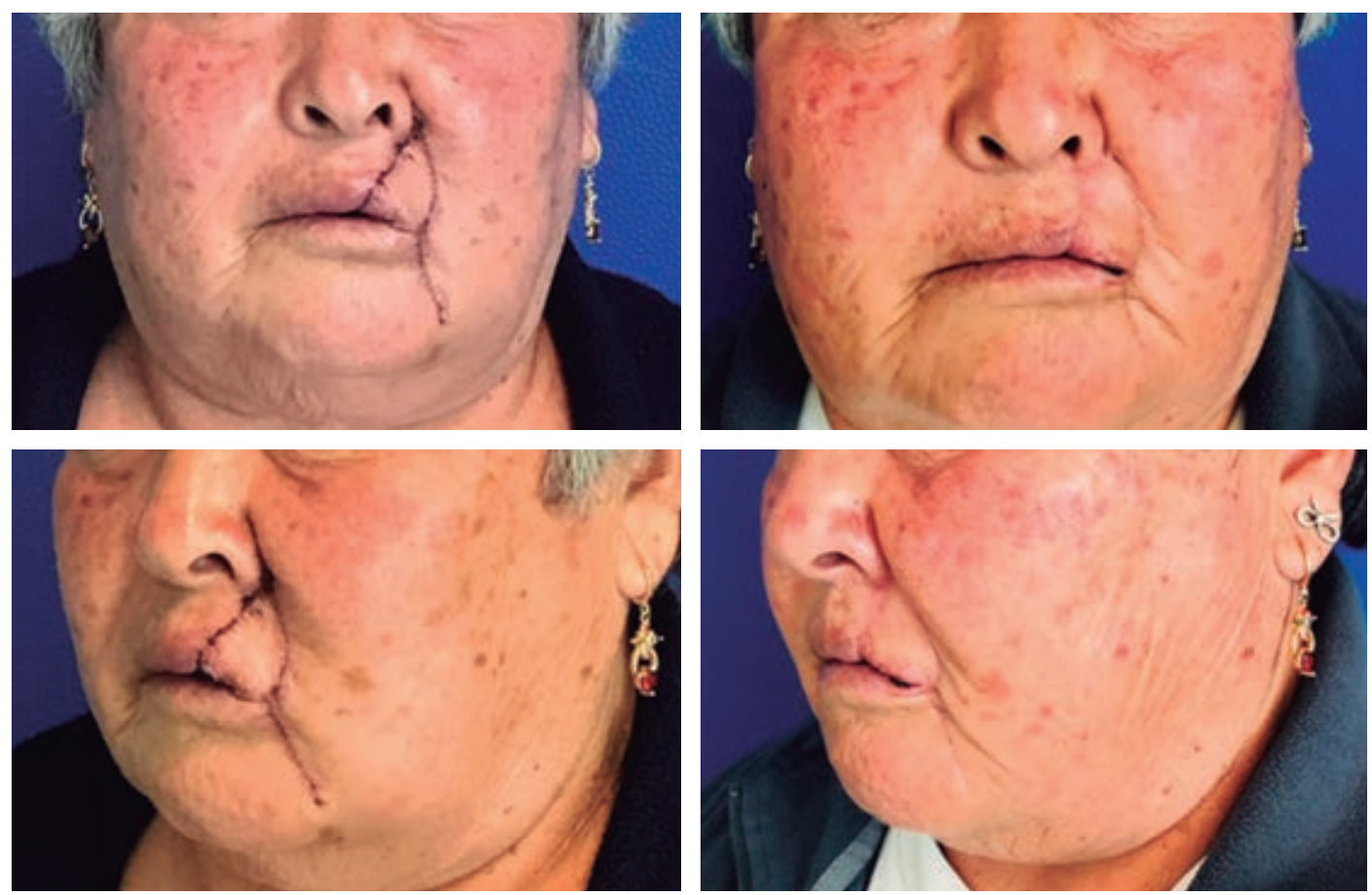

\section{Figura 8:}

Resultado

postoperatorio a los siete días y seis meses.
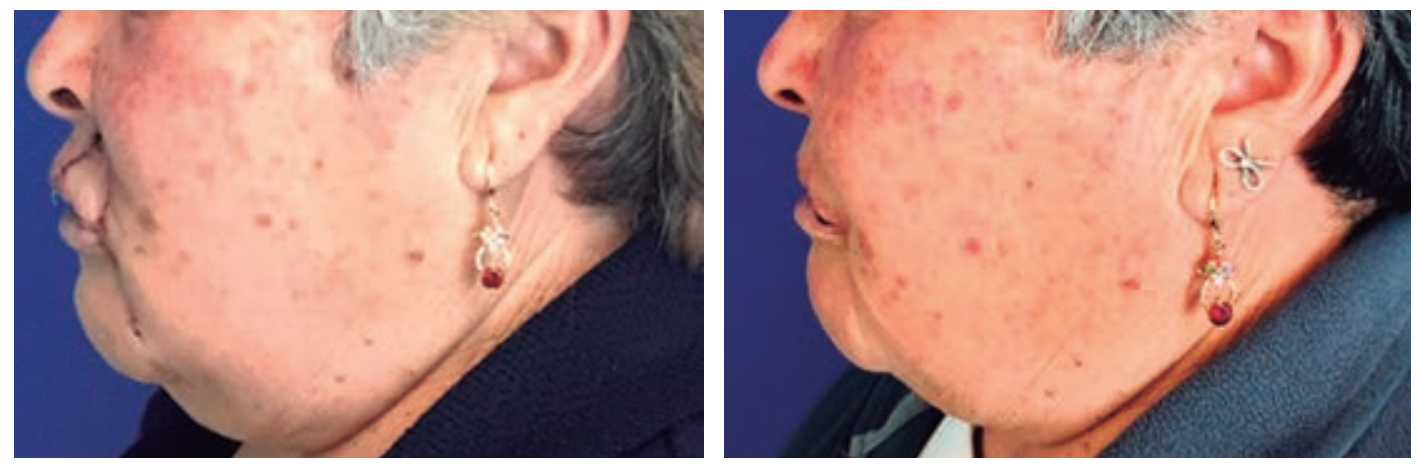

aceptables, con una curación de las heridas en dos semanas después de la intervención y una cicatriz apenas perceptible después de un mes. Asimismo, no presentaron deformidad del filtrum ni microstomía, con una buena función del labio y preservación de la sensibilidad y función motora normal después de seis meses de seguimiento sin la necesidad de realizar un segundo procedimiento quirúrgico; sin embargo, la microstomía postoperatoria debe ser revisada con esta técnica a los tres meses.

Los resultados finales en nuestros pacientes cumplen la mayoría de los principios de reconstrucción, habiendo logrado una completa cubierta cutánea y revestimiento oral, adecuada apariencia del bermellón, diámetro estomal adecuado, sensación preservada y esfínter oral competente, por lo que no se requirió un segundo procedimiento.

En nuestros pacientes, la cicatrización de las heridas se logró dos semanas después de la intervención y la cicatriz apenas se notó después de un mes.

\section{CONCLUSIONES}

El colgajo Estlander es adecuado para defectos que involucran uno o dos tercios de los labios con afectación de la comisura labial. También se puede usar para la reconstrucción primaria de los labios o la reparación secundaria de defectos de la comisura oral. Esta técnica es 


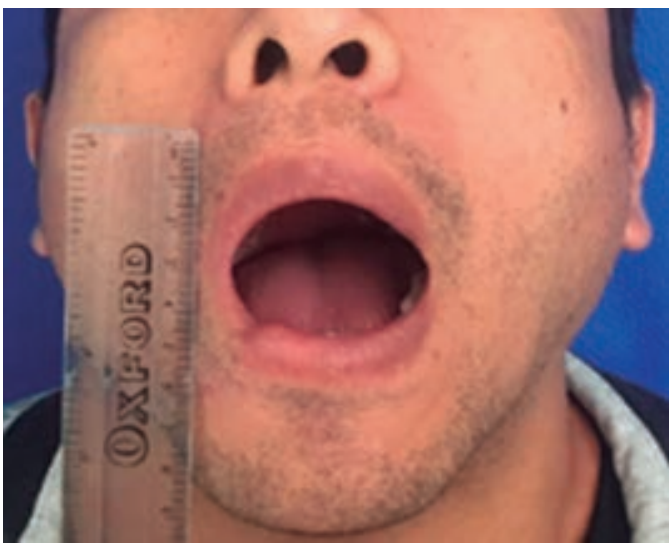

Figura 9: Apertura oral conservada con aspecto romo.

cosmética y funcionalmente exitosa, lo que resulta en una buena simetría de la comisura labial.

El colgajo de Abbe-Estlander es una buena opción para la reconstrucción de defectos laterales o comisurales del labio inferior y superior. La técnica con un colgajo de espesor completo del labio opuesto, como el colgajo Estlander, es un enfoque racional para preservar las unidades estéticas de la cara y su función.

Siempre se debe tomar en cuenta que la arteria labial originada de forma bilateral es inconstante, por lo que si nos basamos en un colgajo pediculado o axial como Abbe, Estlander y McGregor, puede ser comprometido.

\section{REFERENCIAS}

1. Husein-ElAhmed H, Armijo-Lozano R. Lower lip reconstruction using a skin-mucosa Abbe-Estlander flap after squamous cell carcinoma excision. Ann Bras Dermatol 2017; 92 (2): 260-262.

2. Cheng CY, Fang HW. Old age lower lip cancer defects reconstruction by Abbe-Estlander flap. Int J Gerontol 2018; 12 (2): 160-163.

3. Demetrius M, Coombs BS, Debra A. Reconstructing defects of the lower lip: an emphasis on the Estlander flap. Interesting Case, Eplastia 2016; 16: e50

4. Alvarez GS, Siqueira EJ, de Oliveira MP. A new technique for reconstruction of lower lops and labial commissure defect: a proposal for de association of Abbe-Estlander and Vermilion mucosal flap techniques. Oral Maxillofac Surg 2013; 115 (6): 274-730.
5. Uglesic V, Amin K, Dediol E, Kosutic D. Combined Karapandzic-Abbe/Estlander/Stein flap for subtotal and total lower lip reconstruction. J Plast Reconstr Aesthet Surg 2019; 72 (3): 484-490. doi: 10.1016 / j.bjps.2018.11.005.

6. Ebrahimi A, Maghsoudnia GR. Prospective comparative study of lower lip defects reconstruction with different local flaps. J Craniofac Surg 2011; 22 (6): 2255-2259.

7. Kumar A, Shetty PM, Suhas BR, Redddy GS, Mohan $\mathrm{KR}$, Kumar H. Versatility of Abbe-Estlander flap in lip reconstruction- a prospective clinical study. J Clin Diagn Res 2014; 8 (10): 18-21.

8. Huang MHS, Lee, ST, Lee SJ. Comprehensive cleft care. Chapter 6: anatomy of cleft lip and palate. New York: Thieme, 2016, pp. 89-96.

9. Salibian AA, Zide BM. Elegance in upper lip reconstruction. Plast Reconstr Surg 2019; 143: 572.

10. Templer J, Renner G, Davis WE, Thomas JR. "How do I do it" - plastic surgery. Practical tips on facial plastic surgery. A modification of the Abbe-Estlander flap for lower lip defects. Largincoscope 1981; 9 (1): 153-156.

11. Genc S, Ugur SS, Arslan IB, Tuhanioglu B, Demir A, Selcuk A. Lower lip reconstruction with Abbe-Estlander flap modification: preserving the same side vascular pedicle. Eur Arch Otorinolaringol 2012; 269 (12): 2593-2594.

12. Roldan JC, Teschke M. Reconstruction of the lower lip: rationale to preserve the aesthetic units of the face. Plast Reconstr Surg 2007; 120 (5): 1231-1239.

13. Ebrahimi A, Motamedi MHK, EbrahimiA, Kazemi M, Shams A, Hasemzadeh H. Lip Reconstruction after tumor ablation. Plast Surg 2016; 5 (1): 15-25.

14. Schulte D, Sherris DA, Kasperbauer JL. Anatomical basis of Abbe' flap. Laryngoscope 2001; 111 (3): 382386.

15. Magden O, Edizer M, Atabey A, Tayfur V, Ergür I. Cadaveric study of the arterial anatomy of the upper lip. Plast Reconstr Surg 2004; 114 (2): 355-359.

16. Brabyn PJ, Muñoz-Guerra MF, Zylberberg I, RodríguezCampo FJ. Lip reconstruction technique: a modified Abbe-Estlander with a myomucosal advancement flap. J Stomatol Oral Maxillofac Surg 2017; 119 (4): 307-310.

17. Yamauchi M, Yotsuanagi T, Ezoe K, Saito T, Yokoi $\mathrm{K}$, Uruschiade S. Estlander flap combined with an extended upper lip flap technique for large defects of lower lip with oral commissure. J Plast Reconstr Aesthet Surg 2009; 62 (8): 997-1003.

Correspondencia:

Dr. Jesús Fernando Romero Espinosa

E-mail: fernandoromeromd@yahoo.com.mx

Conflicto de intereses: Los autores de este artículo no tienen conflicto de intereses que declarar. 